Deindustrialisation and Structural Change During The Post-Communist Transition

\author{
By: Tomasz Mickiewicz and Anna Zalewska
}

Working Paper Number 383

June 2001 


\title{
Deindustrialisation and Structural Change During The Post-Communist Transition*
}

\author{
Tomasz Mickiewict:**, SSEES-University College London
Anna Zalewskaf*, LIFE-Maastricht University, CEPR, CMPO
}

June 2001

\begin{abstract}
The aim of this paper is to model the evolution of employment structure in postcommunist economies in the broader context of deindustrialisation. The paper builds on the model of structural change developed by Rowthorn and Wells (1987). We show that the starting point of high industry sector share in total employment and its direct fall when productivity of sectors changes in favour of services can be explained in terms of this framework. Moreover, the model can also describe the phenomenon of a further expansion of the agriculture, observed in countries classified as "less consistent" in the reforms implementation. Hence, we distinguish two development paths, the efficient one, called "horizontal", and the inefficient one called "vertical". We illustrate it with empirical data, using alternative measures of structural change and patterns of structural evolutions during transition. Finally, we discuss the link between the EBRD indicators of reforms and structural change. We show that the "quality" of reforms, not the initial GDP level determines a country's development path.
\end{abstract}

Keywords: transition economies, employment structures, deindustrialisation, convergence, liberalisation.

\footnotetext{
* The authors would like to express gratitude for critical comments on earlier versions to Janice Bell, Wendy Carlin, Paul Grout, Milan Nikolic and Slavo Radosevic.

** Tomasz Mickiewicz, SSEES, University College London, Senate House, Malet Street, London WC1E 7HU, U.K, ,e-mail: t.mickiewicz@,ssees.ac.uk, phone: + 44 (0) 207862 8606, fax: + 44 (0) 207 8628642
}

\footnotetext{
*** Anna Zalewska-Mitura, LIFE, Maastricht University, P.O. Box 616, 6200 MD Maastricht, NL, e-mail: a.zalewska@,berfin.unimaas.nl, phone: + 31 (0) 43388 3637, fax: + 31 (0) 433884875
} 


\section{NON-TECHNICAL SUMMARY}

The structural characteristics of employment are one of the main indicators of country's development in the long run. The share of industry, agriculture and services in global employment, occupational categories, distribution of skills, education and human capital are factors commonly taken as indicators of a country's place on an evolution ladder. In the context of post-communist transition, it became standard to link the process of development to the shifts in employment structure in terms of public and private sectors. We break with this tradition and introduce to the debate three sectors: agriculture, industry and services. It is a common knowledge that high ratios of employment in both service and industry sectors characterise high-income economies. On the over hand, low-income economies are mainly agricultural. This simple observation arises a question of how countries shift from a position of underdeveloped agriculture based systems to modern, urbanised economies; what is the optimal path for such a transformation and how it can be attained.

The post-communist countries have been characterised by an exceptionally high share of industry. The economic reforms, which came as a consequence of the "regime switch", imposed structural changes leading to an immediate decrease of industry share. However, growth of the service sector is not the common case. In this respect, the post-Soviet block is highly heterogeneous. There are countries (i.e. the Czech Republic, Hungary, Poland), which seem to be restructuring their economies successfully. Those counties are characterised by a decrease of industry share in favour of services. At the same time, countries like Bulgaria, Romania, and Russia, experienced an initial increase in an agricultural share as a consequence of a decrease of employment in the industry sector and sluggish growth of their service sectors. Those countries are also classified as less successful in terms of reforms and economic growth. This divergence in transition paths brings to life an issue of what is the optimal path of development and whether a structural change associated with transition can be explained by existing economic growth theories.

We use the Rowthorn and Wells model (1987) of structural change to explain development paths observed in the transition post-communist block. First, we 
demonstrate that the starting point of high industry sector share in total employment and its direct fall when productivity of sectors changes in favour of services can be explained within the framework developed by Rowthorn and Wells for developed countries. Moreover, the model can also describe the phenomenon of a further expansion of the agriculture, observed in countries classified as "less consistent" in the reforms implementation. Hence, we distinguish two development paths, the efficient one, called "horizontal", and the inefficient one called "vertical".

Comparison between ineffcient (vertical) scenario and efficient (horizontal) in the model demonstrates that:

- In the 'inefficient' case, the aggregate production level (GDP) is always lower immediately after the transition,

- The share of industry in employment is lower in the 'ineffcient' scenario; it is equivalent to say that the deindustrialisation process induced by transition is more radical,

- Employment in agriculture is higher in the 'inefficient' case, as implied by lower productivity, given the same level of demand.

Empirical data on the three-sector level is consistent with the model. First, the large initial share of industry implies relatively larger shift in demand parameters after transition, and therefore a greater slump in GDP. Second, inconsistent reforms are directly linked to the lower efficiency of restructuring. In this case, not only the slump in GDP is more dramatic, but also less employment is reallocated towards services ('horizontally') and more towards agriculture ('vertically'). Simple regressions linking the restructuring index, defined by Jackman and Pauna (1997), with different measures of structural reforms developed by EBRD show that the higher quality reforms, the deeper structural adjustment towards more efficient labour allocation. Moreover, the regressions indicate that the initial (at the beginning of reforms implementation) level of GDP per capita does not determine the way a country transforms its employment structures. This brings to the light an argument against overestimating the impact of initial conditions in the post-communist countries. In 
fact, not the starting point, but the direction of change determines the final point. We also conclude that the EBRD "enterprise reform" indicator exhibits a high explanatory power, i.e., corporate reforms play a key role in structural changes. Corporate reforms create potential for microeconomic adjustment and that, in turn, induces needed structural adjustment on macro level.

We disagree with a naïve viewing economic transition as a process of 'creative destruction', which should proceed as fast as possible. Fast deindustrialisation is not an optimal path of transition. To the contrary, it is a sign of inefficient adjustment, where dismantled manufacturing is transformed into new 'rust bets', where former workers revert to survival-type, inefficient agriculture. 
William Davidson Institute Working Paper 383

I. INTRODUCTION 
The structural characteristics of employment are one of the main indicators of country's development in the long run. The share of industry, agriculture and services in global employment, occupational categories, distribution of skills, education and human capital are factors commonly taken as indicators of a country's place on an evolution ladder. In addition, in the context of post-communist transition, it became standard to link the process of development to the shifts in employment structure in terms of public and private sectors. Aghion and Blanchard (1993), Rodrik (1995), Ruggerone (1996), Blanchard (1997), and Driffill and Miller (1998) give a detailed discussion of the economic transition in terms of structural shift from state to private sector. While pioneering in linking structural evolutions and macroeconomic indicators, unemployment in particular, those models do not reach beyond a twosector specification of employment structures.

In this paper we diverge from this tradition. We capture the emergence of unemployment by taking into account downward adjustment in employment rate after transition. However, amongst the economic indicators, the unemployment rate is the one, where transition economies are most convergent (Andreff 1999). Therefore, we do not use unemployment to illustrate differences in adjustment profiles. Instead we focus on structures of employment. To some extend, the approach is akin to Grafe and Wyplosz (1998). Their discussion of a linkage between the real exchange rate and structural changes during transition introduces three sectors: an old state sector and two new sectors (traded and non-traded goods), under an assumption of full employment. Although the model developed by Grafe and Wyplosz shows the importance of traded and non-traded sectors in the new economy, it does not explain what originates and determines optimal (in the sense of timing and size) intra-sectoral shifts. This is a path we are going to step on. More precisely, instead of modelling one transition path, we identify and compare efficient and inefficient routes. We do it using a three-sector model comprising agriculture, industry and services.

Looking at those three sectors has a deep origin in more general studies on a structure of employment in both developed and developing countries. It is a common knowledge that high ratios of employment in both service and industry sectors characterise high-income economies. On the other hand, low-income economies are 
mainly agricultural. This simple observation arises a question of how countries shift from a position of underdeveloped agriculture based systems to modern, urbanised economies; what is the optimal path for such a transformation and how it can be attained. In other words, "structural change of economic organisation", and in particular, "structural change of employment" call for special attention as indicators of a long-term economic development and country's position in the international labour division. It is also an indicator of economy's vivacity and strength. In low-income countries, economic development brings in an immediate increase in share of manufacturing and services at the expense of agriculture. In the later phase of development, the share of industry stabilises, and then falls, while the service sector expands further (Rowthorn and Wells, 1987; Dohrn \& Heilemann, 1993, 1996; EBRD 1997, 1999).

This general characteristic provides a reference point for the analysis of postcommunist transition, the pattern of initial distortions and alternative adjustment paths. As our benchmark, we use a formalisation developed by Rowthorn and Wells (1987). Their model distinguishes between the two stages: first, an increasing importance of the industrial employment during the early phase of development, and next its decline in the post-industrial world. Rowthorn and Wells' influential work was a response to a regression of the industry share experienced by developed, western economies in the 1970s and 1980s, and a contribution to the hot debate on the role and optimal speed of deindustrialisation. In their model, structural change was driven by two factors:

(i) an improvement in productivity, at different rates across sectors (lowest for services),

(ii) differences in income elasticities of demand, with the demand for food being income-inelastic.

In other words, those two factors were sufficient to induce the dynamic structural evolutions, which resulted first in the phase of industrialisation (both, the shares of industry and services in employment grew at cost of agriculture) and than in the phase 
of deindustrialisation (the share of service sector in employment grew at cost of industry). $\stackrel{2}{\square}$

Rowthorn and Wells concluded that the underlying pace of productivity change in different sectors, not just the level of aggregate GDP per capita, should be considered the major driving force of structural change. More explicitly, it is not the case that some countries are poor due to an excessive share of employment in agriculture, but rather that this share is excessive due to low productivity in that sector. Improvement in productivity increases income per capita, which in turn affects the structure of demand and leads to the development of 'new' sectors, services in particular. Due to the fact that many of services are nontradable, structure of production follows domestic demand. This means that the share of services increases more than proportionally with an increase of the real income.

Thus, the link between sectoral employment structures and GDP per capita results from a mixture of demand and supply factors. Capital accumulation, enhancement in human capital, infrastructure, legal and macroeconomic stability, all contribute to increased productivity in agriculture, and next in industry. Reallocation of employment to services (deindustrialisation) represents a mixture of a shift towards more efficient production structures and a response to the shifting pattern of demand.

We place the post-communist transition in the broader context of this model, taking into account the stylised facts. First, that the post-communist countries have been characterised by an exceptionally high share of industry compared with the other lowincome economies. Even more, the share of the industrial sector in global employment has been higher than in many high-income countries. Therefore, a further increase of industry share, as a feature of post-communist adjustment and development, would not only be unnecessary but rather inappropriate.

Second, economic reforms, which came as a consequence of the "regime switch", imposed structural changes leading to an immediate decrease of industry share. However, growth of the service sector is not the common case. In this respect, the post-Soviet block is highly heterogeneous. There are countries (i.e. the Czech 
Republic, Hungary, Poland), which seem to be restructuring their economies successfully. Those counties are characterised by a decrease of industry share in favour of services. At the same time, countries like Bulgaria, Romania, and Russia, experienced an initial increase in an agricultural share as a consequence of a decrease of employment in the industry sector and sluggish growth of their service sectors. Those countries are also classified as less successful in terms of reforms and economic growth. This divergence in transition paths brings to life an issue of what is the optimal path of development and whether a structural change associated with transition can be explained by existing economic growth theories.

We use the Rowthorn and Wells model of structural change to explain development paths observed in the transition post-communist block. First, we demonstrate that the starting point of high industry sector share in total employment and its direct fall when productivity of sectors changes in favour of services can be explained within the framework developed by Rowthorn and Wells for developed countries. Moreover, the model can also describe the phenomenon of a further expansion of the agriculture, observed in countries classified as "less consistent" in the reforms implementation. Hence, we distinguish two development paths, the efficient one, called "horizontal", and the inefficient one called "vertical". To illustrate the aptness of the model we provide an empirical evidence documenting different development paths for selected transition countries.

The paper is organised as follows. Section II opens with a model of the general link between economic development and structures of employment based on work by Rowthorn and Wells (1987). Within the framework a standard path of structural development is defined. Next, the model is used to interpret the post-communist liberalisation (transition) in terms of returning to the standard path of development. Section III gives an empirical evidence of changes in employment in services and industry sectors in transition economies and chosen countries of EU. It defines different types of convergence and shows that data is consistent with the model. Section IV focuses on possible measures of convergence and documents the link 
between efficiency of reforms and the structure of employment using more disaggregate data. And finally, Section V presents conclusions.

\section{THE ROWTHORN-WELLS MODEL AND THE ECONOMIC TRANSITION}

Rowthorn and Wells's (1987) model can be formalised in the following way. Productivity growth in all sectors is given exogenously by:

$$
y_{a}=y_{0} e^{\lambda \alpha t}, \quad y_{i}=y_{0} e^{\lambda \alpha t}, \quad y_{s}=y_{0} e^{\alpha t}
$$

where $y$ stands for labour productivity; subscripts $a, i$ and $s$ relate to agriculture, industry and services respectively. The initial level of productivity at the beginning of the development path is denoted by $y_{0}(>0)$. Parameters $\alpha(>0)$ and $\lambda(>1)$ relate to productivity growth, where the first one determines the general pace of development and the latter corresponds to the sectoral differential. Finally, $t$ denotes time.

Aggregate employment is given by:

$$
L=f N
$$

where, $N$ represents population and $f$ is the employment rate interpreted as a percentage of the total population (not of working age population). This means that $0<f<1$.

Output in agriculture is proportional to the size of population. Therefore, agricultural output and employment are correspondingly given by:

$$
\begin{aligned}
& Z_{a}=\gamma N, \\
& L_{a}=Z_{a} / y_{a,},
\end{aligned}
$$

where, $\gamma$ is a coefficient of demand. Therefore $0<\gamma<y_{0} / f$.

Next, employment and output in services are determined by a second demand condition, which implies that the real output of services $\left(Z_{s}\right)$ is a constant fraction of total output, that is $Z_{S}=c Z$. This puts a restriction on the corresponding demand 
coefficient: $0<c<1$. More formally, employment and output in services can be expressed as:

$$
\begin{aligned}
& L_{s}=\frac{c\left(L_{a} y_{a}+L y_{i}-L_{a} y_{i}\right)}{y_{s}+c y_{i}-c y_{s}}=\frac{c L y_{i}}{y_{s}+c\left(y_{i}-y_{s}\right)} \\
& Z_{s}=L_{s} y_{s}
\end{aligned}
$$

Finally, the employed and output in industry are determined as:

$$
\begin{aligned}
& L_{i}=L-L_{a}-L_{s} \\
& Z_{i}=L_{i} y_{i}
\end{aligned}
$$

Directly from the model specification we can conclude that the aggregate output, $Z$, grows monotonically over time for all possible combinations of values of four other parameters (i.e. $f, \lambda, \gamma$ and $c$ ). To see that, we can present the aggregate output as:

$$
Z(t, f, \lambda, \gamma, c)=Z_{a}+Z_{s}+Z_{i}=f N y_{0} \frac{e^{\lambda \alpha t}}{1-c+c e^{(\lambda-1) \alpha t}}
$$

Then, the time differential, given by

$$
\frac{\partial Z}{\partial t}=f N y_{0} \frac{\alpha e^{\lambda \alpha t}\left[\lambda(1-c)+c e^{(\lambda-1) \alpha t}\right]}{\left(1-c+c e^{(\lambda-1) \alpha t}\right)^{2}}
$$

is always positive, as $c$ was assumed to be less than one. The aggregate effect of economic growth (i.e. of $Z$ ) results from the increase in productivity net of the impact of employment shift to lower productivity services. And the process of economic growth continues uninterrupted.

To demonstrate the structural characteristics of the model, we show how changes in the model parameters (i.e. the employment rate $f$, demand coefficient of agriculture $\gamma$, demand coefficient of services $c$, and productivity differential $\lambda$ ) affect the size of employment of the industry sector. To simplify mathematics, we use the joint share of 
agriculture and services (i.e., one minus share of industry), instead of the total share of industry. That is:

$$
\varphi(t, f, \lambda, \gamma, c)=1-\frac{L_{i}}{L}=\frac{L_{a}+L_{s}}{L}=\frac{\gamma}{f y_{0}} e^{-\lambda \alpha t}+\frac{c e^{(\lambda-1) \alpha t}}{1-c+c e^{(\lambda-1) \alpha t}}
$$

From formula 8 we calculate that

$$
\begin{aligned}
& \frac{\partial \varphi}{\partial f}=-\frac{\gamma}{y_{0} f^{2}} e^{-\lambda \alpha t}<0 \\
& \frac{\partial \varphi}{\partial \gamma}=\frac{1}{y_{0} f} e^{-\lambda \alpha t}>0 \\
& \frac{\partial \varphi}{\partial c}=\frac{e^{(\lambda-1) \alpha t}}{\left(1-c+c e^{(\lambda-1) \alpha t}\right)^{2}}>0 .
\end{aligned}
$$

Thus, the signs of the corresponding partial derivatives are independent of time and of the values of all other parameters, given the assumptions. We observe that the higher employment rates, the higher share of industry in total employment (equation 9). Moreover, the lower preference for both agriculture and service output (equations 10 and 11 respectively), the higher share of industry in total employment. These results are consistent with stylised facts (see for instance: Mickiewicz and Bell, 2000). Prior to transition, employment rates were high and there was a strong preference for industry (more detail discussion to be found in Section III below). The low preference for agriculture might be explained by the fact that the communist policy-makers could 'afford' to maintain lower standards of consumption, without pushing significant groups of people below the poverty level. It was possible due to compressed income structures. Also, the low share of services in consumption may be somehow affected by the compressed income distribution, as a significant share of services could be treated as a 'luxury goods' sector.

In contrast with the previous results, the impact of the shift in productivity differential $\lambda$ on the employment structure depends on values of remaining four parameters. As 
the analysis of this case is more complex, we moved all the details to the Appendix. However, the derivative of $\varphi$ is given by

$$
\frac{\partial \varphi}{\partial \lambda}=(1-c) \alpha t \frac{c e^{(\lambda-1) \alpha t}}{\left(1-c+c e^{(\lambda-1) \alpha t}\right)^{2}}-\frac{\gamma}{f y_{0}} \alpha t e^{-\lambda \alpha t},
$$

which is the difference between the rate of growth of employment in services due to change in productivity differential $\lambda$ (the first term) and the speed of shrinking of agriculture employment due to change in $\lambda$ (the second term). Furthermore, we may focus on the most likely combination of the remaining parameters, for which $\frac{1-c}{2}\left(c^{2}-2 c+3-\sqrt{\left(c^{2}-2 c+3\right)^{2}-4}\right)<\frac{\gamma}{f y_{0}} e^{-\alpha t}<1-c$ holds. In this case, an increase in parameter $\lambda$ results in an increased share of industry for low values of $t$ and in decreased share of industry for high values of $t$. In other words, an increase in a relative productivity of industry increases the share of industry in employment in the early stage of development and decreases this share in an advanced stage. More specifically, $\frac{\partial \varphi}{\partial \lambda}<0$ for all $t$ such that $e^{\alpha \lambda t}<\frac{\left(\gamma / f y_{0}\right)(1-c)+\sqrt{\left(\gamma / f y_{0}\right)(1-c)^{3} e^{\alpha t}}}{1-c-\left(\gamma / f y_{0}\right) c e^{-\alpha t}}$, and $\frac{\partial \varphi}{\partial \lambda}>0$ for all $t$ corresponding to values of $e^{-\alpha \lambda t}$ higher than that expression.

Having comparative results established, we may now define the post-communist transition as a process of convergence towards the optimum development path, once adjustment became possible due to the liberalisation and reforms. In other words, transition is a process of moving towards a development path consistent with the structure of preferences, that is, with both the structure of demand for final products and with preferences behind labour supply decisions. Thus, an effect of transition is that the policy favouritism for industry is replaced by a market structure of demand (parameters $\gamma$ and $c$ should become bigger). Simultaneously, there is a decrease in employment rate $(f)$. All these shifts in parameters lead to the decrease in the share of industry employment, as shown by equations 9-11. 
Another aspect of transition is its impact on total production (GDP), denoted by Z. To see the possible changes in the aggregate output let us look at the following derivatives:

$$
\begin{aligned}
& \frac{\partial Z}{\partial f}=N y_{0} \frac{e^{\lambda \alpha t}}{\left(1-c+c e^{(\lambda-1) \alpha t}\right)}>0 \\
& \frac{\partial Z}{\partial \gamma}=0 \\
& \frac{\partial Z}{\partial c}=-f N y_{0} e^{\lambda \alpha t} \frac{e^{(\lambda-1) \alpha t}-1}{1+c\left(e^{(\lambda-1) \alpha t}-1\right)}<0
\end{aligned}
$$

From equation 14 we see that the change in $\gamma$ (demand for agricultural products) has no effect on GDP. This is due to the fact that productivities in both agriculture and industry are equal, which implies that the share of services remains unchanged (the latter being determined in relation to aggregate production). However, both the shift in preferences towards services (increase in $c$ ) and lower employment rates $f$ lead to lower GDP. The decrease in GDP coming as a consequence of revealed preferences for services may look inconsistent with intuition. However, at this point we should stress that the decrease in production brought by transition is not equivalent to a real welfare loss. The welfare actually increases, as there was initial inconsistency between preferences and structures of both production and employment in the communist system. The argument is familiar to all those, who followed the early discussion on the 'transitional recession'. What we say is that the slump in production was relatively less serious than asserted, due to the fact that the old structure of production misrepresented population interests. To quote one of the architects and main proponents of reforms:

"... the lost production reflects the cutbacks in production of enterprises that lack customers, mainly the cutback of excessively large heavy industrial sector." (Sachs, 1994, p. 67). 
However, practically all analysts would also agree that the slump in GDP during transition does reflect some real effects. To explain this, we have to extend the framework used so far. Part of the decrease in GDP would correspond to short-term effects related to the impact of stabilisation programmes, which we do not consider here. However, there are also negative effects from the reallocation of the labour force, ${ }^{6}$ with productivity losses, which may result from the reallocation process. In general, the reallocation process is inefficient if productivity-enhancing restructuring does not support the movement of labour.

To illustrate this let us consider a situation when only a shift in parameter $\gamma$ occurs. As already discussed no loss of productivity should be expected in this case (as the share of low productivity sector in output remains the same). At the same time, some initial reallocation of labour towards agriculture should be observed, because transition corresponds to the increase in $\gamma$.

To have a deeper insight into the problem, let us modify the benchmark model, so we can illustrate the case, in which the reallocation of labour is not sufficiently supported by restructuring. In this instance, the average productivity in 'receiving' sector (in this example: agriculture) decreases. Thus, let us assume that in this 'inefficient' case the post-reallocation productivities are no longer given by equation (1), but they are replaced by:

$$
y_{a}=y_{0} e^{\alpha t}, \quad y_{i}=y_{0} e^{\lambda \alpha t}, \quad y_{s}=y_{0} e^{\alpha t} \quad\left(y_{0}>0, \alpha>0, \lambda>1\right) .
$$

The combined share of agriculture and services in employment (i.e. one minus industry) becomes:

$$
\psi(t, f, \lambda, \gamma, c)=1-\frac{L_{i}}{L}=\frac{L_{a}+L_{s}}{L}=\frac{\gamma}{f y_{0}} e^{-\alpha t}+\frac{c}{f y_{0}} \frac{\gamma+f y_{0} e^{\lambda \alpha t}-\gamma e^{(\lambda-1) \alpha t}}{e^{\alpha t}(1-c)+c e^{\lambda \alpha t}}
$$

By comparison of function $\varphi$ (equation 8, 'efficient' reallocation) and function $\psi$ (equation 8', 'inefficient' reallocation) it gets clear that the share of industry in the second case is always smaller. That also proves that the aggregate production level $(Z)$ 
would be lower for the post-reallocation economy described by equations ( $\left.1^{\prime}\right)$. This is because industry alone would retain the position of the highest productivity sector.

In addition, the resulting share of agriculture in the inefficient case, $\psi$, is always higher, as

$$
\left(\frac{L_{a}}{L}\right)_{\varphi}=\frac{\gamma}{f y_{0}} e^{-\alpha \lambda t}<\frac{\gamma}{f y_{0}} e^{-\alpha t}=\left(\frac{L_{a}}{L}\right)_{\psi}
$$

and the share of services is always lower, as

$$
\left(\frac{L_{s}}{L}\right)_{\varphi}=\frac{c f N e^{\alpha \lambda t}}{e^{\alpha t}+c\left(e^{\alpha \lambda t}-e^{\alpha t}\right)}>\frac{c N\left(\gamma+f y_{0} e^{\alpha \lambda t}-\gamma e^{\alpha t(\lambda-1)}\right)}{y_{0}\left[e^{\alpha t}+c\left(e^{\alpha \lambda t}-e^{\alpha t}\right)\right]}=\left(\frac{L_{s}}{L}\right)_{\psi} .
$$

To summarise the comparison, in relation to structures and output level, we get:

$$
\begin{aligned}
& \left(L_{i} / L\right)_{\psi}<\left(L_{i} / L\right)_{\varphi} \quad\left(L_{a} / L\right)_{\psi}>\left(L_{a} / L\right)_{\varphi} \quad\left(L_{S} / L\right)_{\psi}<\left(L_{S} / L\right)_{\varphi} \\
& Z_{\psi}<Z_{\varphi}
\end{aligned}
$$

Thus, for the case where the reallocation process is inefficient (equation 1'), several interrelated results may be established, in comparison with the efficient scenario (as defined by equation 1$)$ :

- In the 'inefficient' case, the aggregate production level (GDP) is always lower immediately after the transition,

- The share of industry in total employment is lower in the 'inefficient' scenario; it is equivalent to say that the deindustrialisation process induced by transition is more radical,

- Employment in agriculture is higher in the 'inefficient' case, as implied by lower productivity, given the same level of demand.

We refer to 'inefficient' adjustment as 'vertical' convergence, in contrast to 'efficient' transition, which will be labelled a 'horizontal' convergence. The intuition behind those terms will be explored in the next section. 
To close the analysis of transition, let us sketch a third alternative interpretation consistent with this theoretical framework. Let us notice that 'efficient' transition can alternatively be interpreted as an upward shift in parameter $\lambda$, that is an increase in the relative productivity of industry (manufacturing) and agriculture. This is consistent with our model because

$$
\frac{\partial Z}{\partial \lambda}=f N y_{0} \alpha t e^{\lambda \alpha t} \frac{1-c}{\left(1-c+c e^{(\lambda-1) \alpha t}\right)^{2}}>0
$$

In other words, an improvement in relative productivity has always a positive effect on the aggregate level of production. It proves that secondary structural effects (increase in the share of services) are weaker than primary effects (higher productivity). Thus, if the transition process is accompanied by the relative increase in the productivity of manufacturing, this effect may (partly) offset both the negative effect of demand-led adjustment as denoted by equations 9 and 10, and loss of efficiency due to reallocation (21).

In addition, as established earlier, we should expect that a positive shift in $\lambda$ would induce increase in the share of industry in countries, which are not yet in the advanced stage of development. Therefore, in the case of transition countries, this effect may partially offset the impact of shifts in other parameters, which were discussed above. Thus, also in this sub-model, the basic conclusion would hold: in countries, where reforms were more efficient, both the decrease in the share of industry would be smaller and the drop in GDP lower.

\section{STRUCTURES OF PRODUCTION, 'HORIZONTAL' VERSUS 'VERTICAL'} ADJUSTMENT

As already discussed, in all countries of the post-Soviet block the share of industry in total employment was much higher than for comparator countries with a similar level of income per capita ${ }^{6}$ This is illustrated by the figure below: 


\section{Figure 1. GDP per capita and share of industry, 1990, 71 countries}

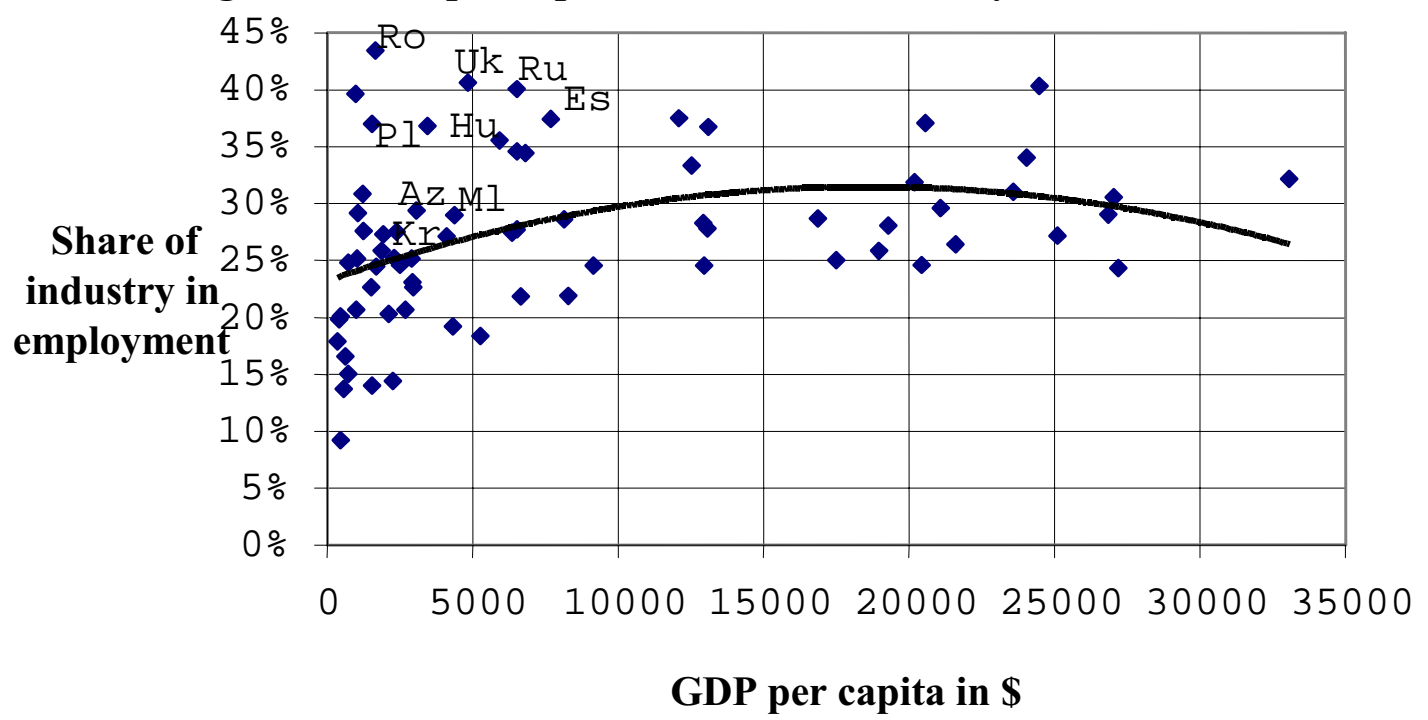

Source: UN, Statistical Yearbook 1995, New York 1997 and WIIW database.

The countries with the value of standardised residuals higher than 1.5 times standard deviation are (in order of magnitude): Romania, Morocco (position not indicated on the graph), Ukraine, Poland, Russia and Hungary. Except Morocco, those are all postcommunist countries. Other members of the former Soviet block included in the UN data set are also above the regression curve, including Estonia and three former Soviet Union republics: Azerbaijan, Moldova, Kyrgyzstan. The large share of industry is obviously an explicit effect of the imposed pattern of development under the communism (EBRD, 1997, p.64).

The high employment in industry compared with the employment in services is even more striking when we restrict ourselves to the purely structural plan, plotting both industry and services as percentage points (Figure 2). This is because employment in services and industry is correlated (the shares of both sectors and agriculture must add to one). Again, countries in the (post)-communist group are clear outliers and do not fit the standard pattern of relationship between income per capita and size of industrial sector. 
Figure 2. Employment structures, 1990, 71 countries.

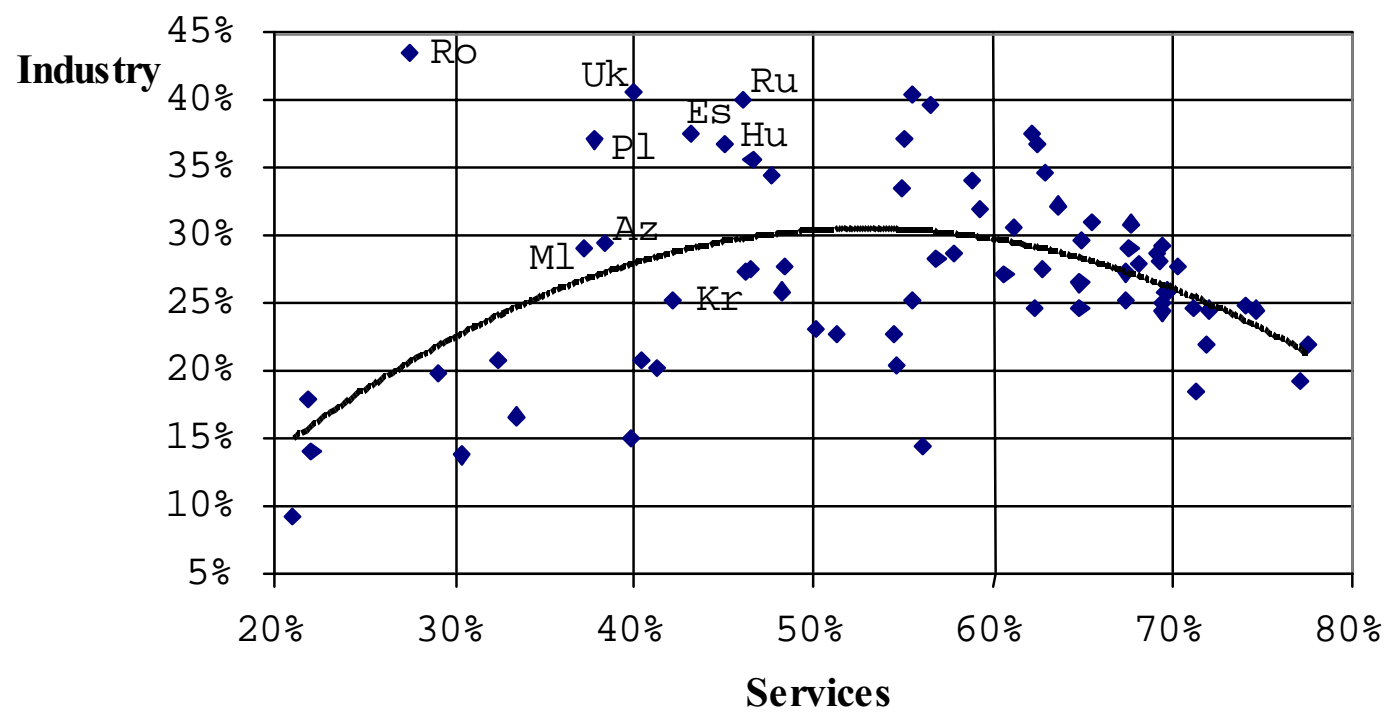

Note: Agriculture (=100\%-industry-services) corresponds to either ISIC2, division 1 or ISIC3, categories $A$ and B; industry means either ISIC2, divisions 2-5, or ISIC3, categories C-F, while services relate to remaining sections

However one could argue that the observed anomaly of the post-communist countries is a result of some more general factors, which are not included in a simple picture presented in Figures 1 and 2. Rowthorn and Wells (1987) stress that the phase of the business cycle (as, say, measured by unemployment indicators), and export specialisation are crucial factors affecting the pace of deindustralisation in highincome countries in a given time point. Dohrn and Heilemann (1996) argue that inclusion of investment, natural resource endowment variables, and exclusion of lowincome countries (for which dispersion is large), are necessary prerequisites of the analysis.

Before we discus those factors in the case of post-communist countries, we should notice that natural resource endowment is correlated with the share of primary sector in exports. This limits the debate to just four possible factors. Moreover, exclusion of low-income countries is problematic, as it affects the generality of conclusions, apparently without justification in existing theory. 
Extension of the other Rowthorn and Wells's arguments in the case of communist countries, is not straightforward either. Specialisation in exports cannot be responsible for over-industrialisation, because the share of exports in GDP was generally low. Those countries followed a strategy of semi-autarchic self-sufficiency. Also, natural resource basis differed significantly within the region, being broad in the former Soviet Union and narrow in Central Europe, hence it cannot explain a common pattern of over-industrialisation.

Investment is also a doubtful variable. However investment rates were typically exceptionally high in the early stages of communist development, the analysis of data shows that the empirical picture is more complex:

- the typical range of investment share in GDP was $24-38 \%$ for communist countries, yet several fast-growing non-communist countries were characterised by similar rates (esp. Far East); on the other hand, one of the most industrialised communist country, East Germany had notably low rates of investment (Gregory, Stuart, 1995, Chapter 12),

- the investment rates decreased significantly in the final stage of communism, in particular during the 1980-ties in Central Europe. Gomulka (1991) documents that most of those economies faced a dramatic shift in policy around 1980. Between 1978 and 1994, the level of investment in communist Central and Eastern Europe was cut by one third. The change was even more dramatic in Poland and Hungary. While the first economy faced almost $60 \%$ cut in investment, the latter experienced a cut by nearly two thirds. At the same time there was no significant adjustment in employment in industrial sectors. 
Thus, in line with Figures 1 and 2, we argue that over-industrialisation in the communist countries resulted not only from the direct impact of the capital accumulation, but also from the more fundamental choice of the model of development. The priority given to industry can be traced back to the ideological discussions, which accompanied the origins of the Soviet model in 1920s. The model, which emerged in the Soviet Union and was subsequently copied in all countries under the Russian domination, gave the priority to industry over agriculture and services and - within industry itself - to heavy industry at cost of consumer-oriented branches (Gregory, Stuart, 1995). Over-industrialisation has been a consequence of military aspirations and import-subsidisation strategy. In addition, a part of large industrial employment was due to labour hoarding, which was presumably greater than in services.

Figure 3 presents basic data on structural evolutions in Central and Eastern Europe, with several other comparator countries.

Figure 3 Structural changes, 1989-1998

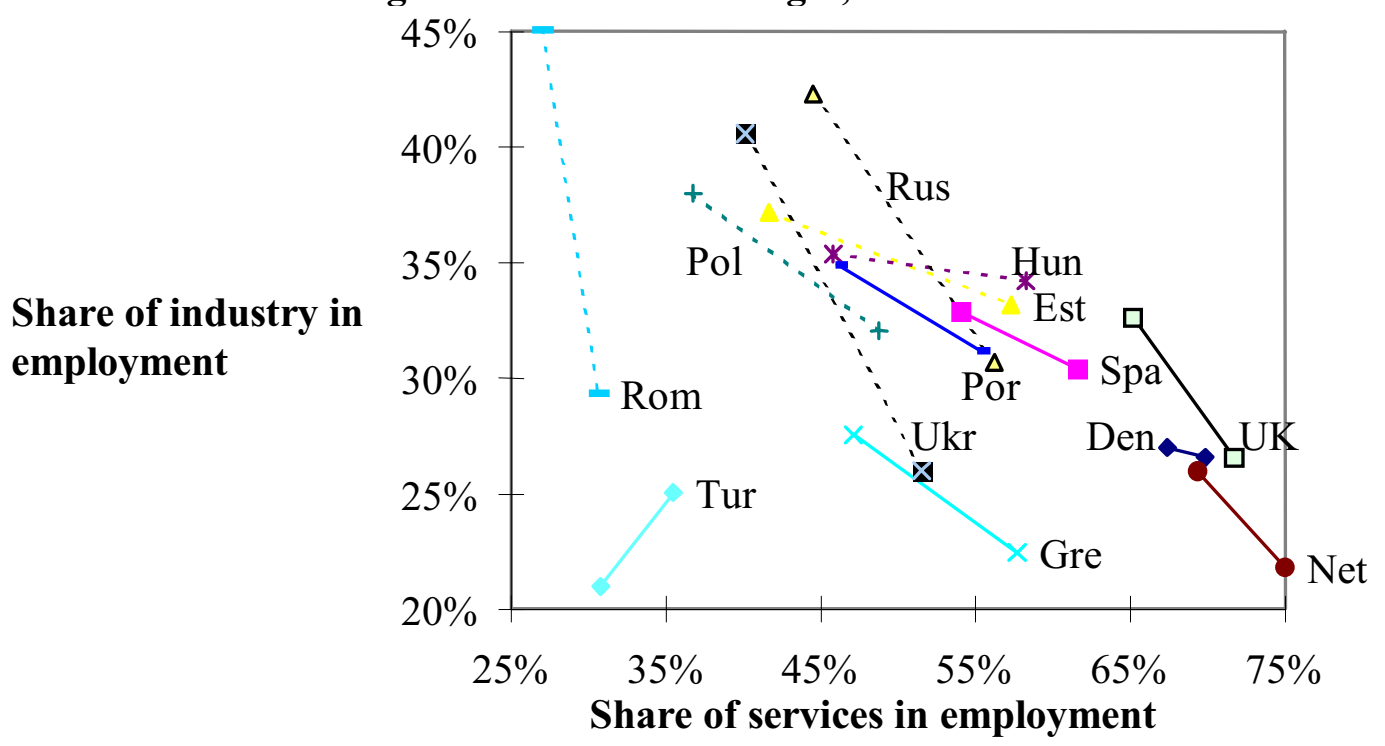

Source: International Labour Office, 1998,1999, Yearbook of Labour Statistics, Geneva WIIW database. The same sources are used in all subsequent tables and graphs. Note: Greece, Portugal - 1989/1997, Russia, Ukraine: 1990/1998. 
It is easy to observe that the share of services in employment increased everywhere, that is, the direction of change is always from left to right, with the first point representing 1989 and the second point corresponding to 1998. Moreover, the measure of slope matters. If the slope is positive, then both the share of industry and of services increased (Turkey). If the slope is negative, the share of industry decreases and we have two further cases. First, if the ratio of growth in services relative to the decrease in industry is high, a share of agriculture decreases. On the contrary, a relatively steep slope would represent an increased share of agriculture, which corresponds to a deindustrialisation not matched by growth in services. That second case describes the situation in Romania, Ukraine and Russia. In Russia, the share of agriculture in employment increased from $13.2 \%$ in 1990 to $15.4 \%$ in 1994 and next started to fall, back to $13.0 \%$ in 1998 (WIIW database). It is interesting to notice that the three latter economies were also characterised by the largest initial shares of industry in employment, the least persistent reform efforts and the largest slump in GDP.

All this is consistent with the model discussed in the previous section. First, the large initial share of industry implies relatively larger shift in demand parameters after transition, and therefore a greater slump in GDP. Second, inconsistent reforms may be directly linked to the lower efficiency of restructuring. That corresponds to 'vertical' adjustment (equivalent to $\psi$ in the previous section). In this case, not only the slump in GDP is more dramatic, but also less employment is reallocated towards services ('horizontally') and more towards agriculture ('vertically').

In Figure 3, the length of the vector may be interpreted as a measure of structural change

$$
d(i, s)=\left(\left|i_{97}-i_{89}\right|^{2}+\left|s_{97}-s_{89}\right|^{2}\right)^{1 / 2}
$$

where $i$ corresponds to the share of industry in employment and $s$ to the share of services. In general, the pace of structural change (as measured directly by the size of the vector) was faster in transition economies than in the comparator economies presented on Figure 3. And amongst the transition economies, it was fastest in those economies characterised by inconsistent reforms (Romania, Ukraine, Russia). 
Poland, Hungary and Estonia started with fairly similar structures of employment (relatively high shares in industry, yet slightly lower than in the three other transition economies mentioned above) and currently they all seem to be converging towards the EU countries represented on the graph. Noticeably, the three CEE countries are very close to the two South European 'cohesion' countries, Portugal and Spain. Also, the process of change in Central Europe did not consist of rapid deindustrialisation, as represented by the relatively flat slopes of the vectors (see next section).

Both central and southern European economies appear to be following a course similar to the earlier development path of three north European economies: Netherlands, Denmark and the UK. Yet, between 1989 and 1998, the pace of change in those three was slow (again, as measured by the length of the vectors), with almost no change in Denmark, mild adjustment in Netherlands and relatively faster deindustrialisation in the $\mathrm{UK}$, resulting in convergence towards the other two countries. Greece seems to be on a different path, parallel to all the above but characterised by a much lower share of industry.

\section{SECTORAL ADJUSTMENT AND REFORMS}

As discussed already, we interpret the structural dimension of the economic transition as an adjustment process towards the production profile consistent with the existing structure of preferences. Higher efficiency of the process is implied by successful reforms, which result in higher productivity of reallocated labour. That, in turn, enables more 'advanced' structures of employment (no increase in the share of agriculture in employment) and a higher GDP level.

So far, we used a three-sector classification to illustrate this effect. However, this section shows that the two alternative paths of structural adjustment (i.e. 'horizontal' and 'vertical') may also be identified on a more disaggregated level, namely using ISIC-3 categories of employment. 'Efficient' structural evolution will now be identified as convergence towards the more developed market economies. We will go beyond the description and exploit the resulting indices to estimate the link between reforms and convergence. 
Therefore, we use the employment structures of the selected EU countries to assess the direction of structural change in transition economies. We interpret a change convergent towards the EU structures as being equivalent to what was described as 'horizontal' convergence in the previous section. The measure of this process, the 'restructuring index' (RI), is taken from Jackman and Pauna (1997). It is defined as "a proportion of the workforce in each country which would need to change sector to enable the country to attain the same structure of employment as that of a comparable Western European economy" (Ibid., p.377) ${ }^{10}$ Thus, the restructuring index has a straightforward, intuitive interpretation, in terms of the extent of inter-sectoral reallocation of the labour force. A lower value of the index corresponds to a need for less restructuring in order to attain convergence. Based on the above definition, the formula for RI, for a given country $a$ and a comparative structure $c$, can be written as:

$$
R I=\frac{\sum\left|s_{i}^{c}-s_{i}^{a}\right|}{2},
$$

where $s$ relates to shares in employment of sectors $i$.

Following Jackman and Pauna (1997), we use the average of four high-income northern EU economies (Germany, UK, Denmark and Netherlands) as the benchmark. ${ }^{12}$ Results are presented in Table 1.

TABLE 1

RESTRUCTURING INDICES: 1994 AND 1998

\begin{tabular}{lll}
\hline Country & RI-N94 & RI-N98 \\
\hline Bulgaria & $\cdot$ & $31.1 \%$ \\
Croatia & $\cdot$ & $15.9 \%$ \\
Czech Republic & $20.5 \%$ & $18.5 \%$ \\
Hungary & $19.8 \%$ & $17.2 \%$ \\
Poland & $27.0 \%$ & $21.5 \%$ \\
Romania & $44.9 \%$ & $42.5 \%$ \\
Slovakia & $23.2 \%$ & $19.5 \%$ \\
Slovenia & $25.4 \%$ & $23.6 \%$ \\
Estonia & $20.0 \%$ & $18.1 \%$ \\
Latvia & $\cdot$ & $24.1 \%$ \\
Lithuania &. & $21.6 \%$ \\
Spain & $17.2 \%$ & $15.0 \%$ \\
Greece & $23.0 \%$ & $22.9 \%$ \\
Portugal & $17.6 \%$ & $18.3 \%$ \\
\hline Note: Czech Republic, Latvia, Greece, Portugal: 1997.
\end{tabular}


All Central European transition countries have made some progress in restructuring, with Croatia, Hungary and Estonia being closest to structures found in the Northern EU. This is entirely consistent with Figure 3. Romania is a clear outlier, with employment structures farthest from the EU. Yet a comparison with Figure 3 reveals different results for the three South European countries. While Spain is converging (with the 1997 index lower than 1994), there is no indication of a convergent change in either Greece or Portugal. Even if the service sector is growing in these two countries (Figure 3), this change has not been convergent recently in terms of the composition of the service sector.

In section II, we discussed the case, where the structures of employment after transition are affected not only by the countries' initial income per capita (as those should determine preference-consistent production structures, as illustrated by Figure 1) by also by the efficiency of the reallocation process (equations 16-18). If the efficiency of reallocation is high, it results in 'horizontal' adjustment. We linked the latter to the reform process, and this is the issue, which we wish to explore now.

Table 2 presents results of our regressions, in which 1998 restructuring index $R I$ is a dependent variable, and two different measures of structural reforms are used as the independent variables. A GDP per capita level is a control variable. The most widely used aggregate measure of institutional reform is the one constructed annually by the European Bank of Reconstruction and Development. Therefore, the average values of eight indicators measuring the progress of transition (EBRD 1999, Table 2.1, page 24) were used as an explanatory variable ${ }^{14}$ in equations $1-3$.

However, we also looked at the correlation coefficients between the structural indicators (RI) and all eight indices separately. The results suggest that "large-scale privatisation", "small-scale privatisation" and "governance and restructuring" are the three most important factors. Together, they form a group of indices described jointly in the EBRD reports as 'enterprise reform'. It leads us to a conclusion that progress in 
sectoral employment restructuring is predominantly related to privatisation and corporate governance reforms. Therefore, we narrowed down our search and looked for a link between restructuring and the average of the three enterprise reform indicators. The results are presented in equations 4-6.

TABLE 2

RI EXPLAINED BY TRANSITION INDICATORS, EU ACCESSION CRITERIA AND GDP PER CAPITA

\begin{tabular}{|c|c|c|c|c|c|c|}
\hline & (1) & (2) & (3) & $(4)$ & $(5)$ & $(6)$ \\
\hline Constant & $\begin{array}{c}0.88 \\
(0.17)^{\star * *}\end{array}$ & $\begin{array}{c}0.91 \\
(0.20)^{\star *}\end{array}$ & $\begin{array}{c}0.88 \\
(0.17)^{\star \star *}\end{array}$ & $\begin{array}{c}0.83 \\
(0.13)^{\star * *}\end{array}$ & $\begin{array}{c}0.87 \\
(0.14)^{\star \star \star}\end{array}$ & $\begin{array}{c}0.83 \\
(0.13)^{\star \star *}\end{array}$ \\
\hline $\begin{array}{l}\text { Average } \\
\text { of } 8 \text { EBRD } \\
\text { indicators, } \\
1998\end{array}$ & $\begin{array}{c}-0.15 \\
(0.04)^{*}\end{array}$ & $\begin{array}{c}-0.17 \\
(0.05)^{*}\end{array}$ & $\begin{array}{c}-0.16 \\
(0.04)^{\star \star *}\end{array}$ & & & \\
\hline $\begin{array}{l}\text { Average } \\
\text { of } 3 \text { EBRD } \\
\text { indicators } \\
\text { (enterprise), } \\
1998\end{array}$ & & & & $\begin{array}{c}-0.17 \\
(0.04)^{\star *}\end{array}$ & $\begin{array}{c}-0.20 \\
(0.05)^{\star *}\end{array}$ & $\begin{array}{c}-0.17 \\
(0.04)^{\star *}\end{array}$ \\
\hline $\begin{array}{l}\text { GDP per } \\
\text { capita, } \\
\text { thousands } \$ \text {, } \\
1990\end{array}$ & $-0.01(0.01)$ & & & $\begin{array}{l}-0.00 \\
(0.01)\end{array}$ & & \\
\hline $\begin{array}{l}\text { GDP per } \\
\text { capita, } \\
\text { thousands } \$ \text {, } \\
1998\end{array}$ & & $\begin{array}{l}-0.00 \\
(0.00)\end{array}$ & & & $\begin{array}{l}-0.00 \\
(0.01)\end{array}$ & \\
\hline $\mathrm{R}^{2}$ & 0.65 & 0.62 & 0.61 & 0.73 & 0.72 & 0.70 \\
\hline Adjusted $\mathrm{R}^{2}$ & 0.57 & 0.53 & 0.57 & 0.66 & 0.65 & 0.67 \\
\hline F -statistics & $7.58^{*}$ & $6.53^{*}$ & $14.3^{* * *}$ & $10.62^{*}$ & $10.38^{*}$ & $21.1^{\text {** }}$ \\
\hline $\begin{array}{l}\text { Number of } \\
\text { observations }\end{array}$ & 11 & 11 & 11 & 11 & 11 & 11 \\
\hline
\end{tabular}

Notes: LOS, standard errors in parentheses; * - significant below 0.05 level; ** - significant below 0.005 level; *** - significant below 0.001 level. GDP data: 1990 from UN Statistical Yearbook 1995 pp. 159176, 1998 from World Bank Atlas 2000 pp. 42-43.

All the results should be considered tentative, as the number of observations is low. The results reveal that income levels are not strong predictors for structures. However, structural evolutions in transition countries seem to be affected more by the speed and quality of reforms that by the GDP levels. Both the initial level of GDP per capita and its contemporary level do not significantly affect the structural indicators. This may indicate that the structural characteristics of the transition economies are not determined by the initial conditions. Moreover, those economies are still adjusting towards 'normal' structures corresponding to GDP per capita and their relative positions on the adjustment paths are determined by efficiency of restructuring, which 
in turn is affected by quality of reforms. Despite small number of observations (11) and controlling for income levels, the reform measure is significant.

The two economies with highest residuals are Romania and Croatia. Romania may be directly compared with Bulgaria: both have been lagging in reforms, yet the latter economy scores better on the structural dimension (lower value of $R I$ represents more convergent structures, as discussed). In contrast, Croatia is characterised by more convergent structures than predicted. Yet, both economies have the value of standardised residuals below two, so there is no reason to exclude them as outliers.

To illustrate the fitness of our regressions we present equations 3 and 6 in a graphical form (Figures 4 and 5).

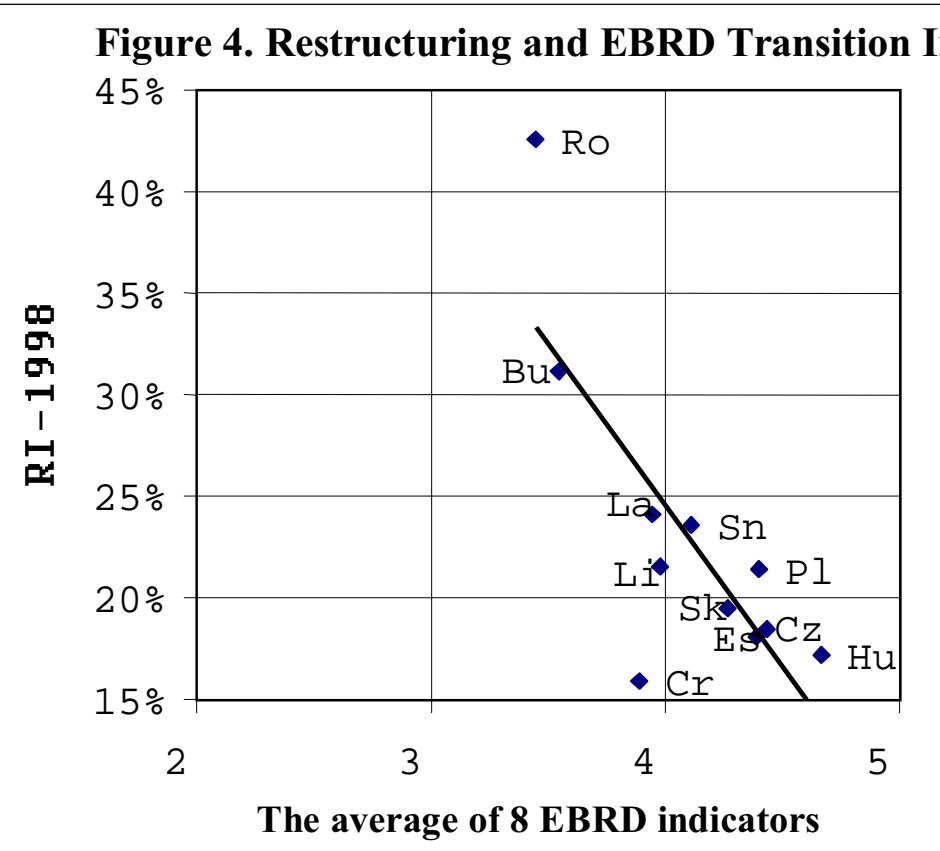

Figure 5: Restructuring and Enterprise Reform

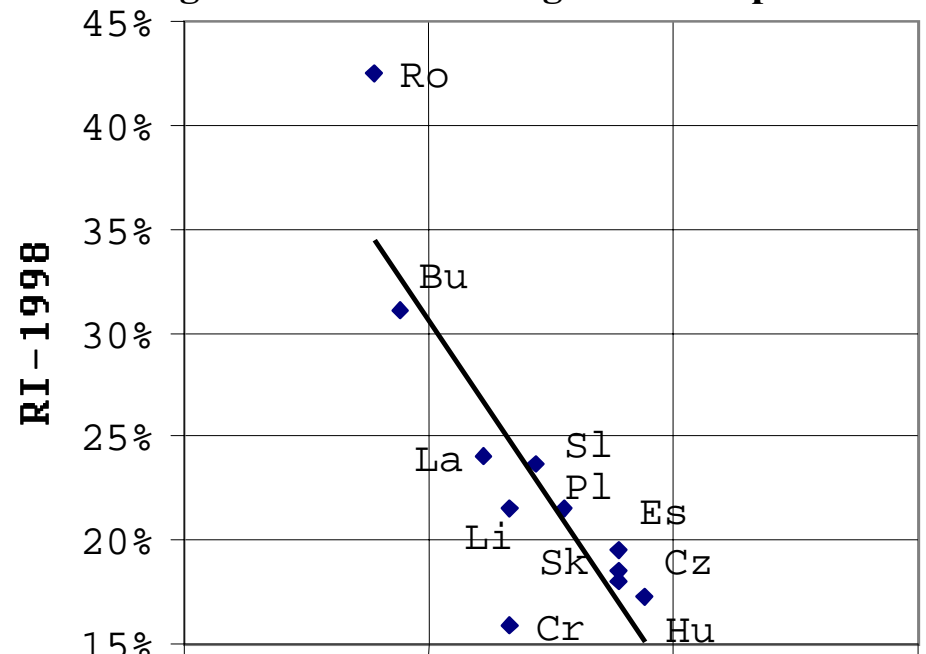


Equations with the "enterprise reform" indices as an independent variable have the greater explanatory power. This gives the basis to, hypothesise that enterprise reform is mostly responsible for the restructuring processes. The location of a transition economy on a spectrum between deindustrialisation ('vertical' adjustment) and successful convergence with the EU ('horizontal' adjustment) seems to be determined by the extent to which reforms have been introduced and in particular, by the extent to which the enterprise reform has been successfully implemented. Reform of corporate governance is crucial for efficient downsizing of the "old" sector. The legal framework, which supports the development of small private firms, is important for the growth of the "new" sectors. 15 It is also important to notice that enterprise reform indicators are related not only to manufacturing but also to agriculture. Slow process of privatisation in agriculture and constraints imposed on private property rights to land may have a negative impact on productivity of agriculture. That in turn may have wider implications both for GDP levels and patterns of structural evolutions, as illustrated by both the model and the empirical link between reforms and RI indices, as discussed in this section. 


\section{CONCLUSIONS.}

From the structural point of view, the post-communist transition may be interpreted as a return from a distorted path of economic development to the one consistent with the existing structure of preferences, that is, with both demand preferences and labour supply. Given the initially distorted structures, this shift leads to fast deindustrialisation and a fall in output. The (already) classical literature on transition analyses the issue as a transfer between the old (state) and newly created (private) sectors. Our research introduces three sectors (industry, agriculture and services) to the debate. The paper defines two paths of structural transformation. A country steps on a "horizontal" path of development if there are no productivity losses from restructuring. It enables the development of service sector. A country following this path changes its employment structures towards those observed in developed countries. In contrast, a country stepping on a "vertical" path of structural adjustment, caused by a low productivity of agriculture and/or manufacturing, suffers from a deeper decline of the aggregate output and faster deindustralisation than a country going along a "horizontal" path. Moreover, such a country experiences a further increase in the agriculture employment. Both of those theoretically defined structural development paths are observed in the post-communist world.

An analysis of country statistics proves that the division of the post-communist block into "horizontal" and "vertical" structural adjustment groups seems right. For instance, the Visegrad countries follow a "horizontal" path, whereas Romania, Ukraine and Russia give evidence of being on the inefficient "vertical" path of structural changes. The latter group, commonly known for its inconsistent implementation of market reforms, is characterised by a big slump of GDP, rapid deindustralisation and initial increase of the agriculture share in the total employment after transition. 
Simple regressions linking the restructuring index, defined by Jackman and Pauna (1997), with different measures of structural reforms developed by EBRD show that the higher quality reforms, the deeper structural adjustment towards more efficient labour allocation. Moreover, the regressions indicate that in comparison with the reforms, the initial (at the beginning of reforms implementation) level of GDP per capita is not a significant factor determining the way a country transforms its employment structures. This brings to the light an argument against overestimating the impact of initial conditions in the post-communist countries. That is, we argue against the type of 'economic fatalism', which is frequently re-emerging in the discussion on the post-communist transition. In fact, not the starting point, but the direction of change determines the final point.

From the regressions we also conclude that the EBRD "enterprise reform" indicator exhibits a high explanatory power. Going further, corporate reforms may play a key role in structural changes. Corporate reforms create potential for microeconomic adjustment and that, in turn, induces needed structural adjustment on a macro level.

We disagree with a naïve viewing economic transition as a process of 'creative destruction', which should proceed as fast as possible. Fast deindustrialisation is not an optimal path of transition. To the contrary, it is a sign of inefficient adjustment, where dismantled manufacturing is transformed into new 'rust bets', where former workers revert to survival-type, inefficient agriculture.

To summarise, we believe that our research starts a new way of looking at the economic restructuring and, in particular, at the role of the agriculture sector in the process of economic development and deindustrialisation of the post-communist countries. At the same time, we want to stress that due to a high diversity of a service sector, a further development of the present model seems necessary. For instance, a distinction between tradable and non-tradable services, with a possible strong productivity gain in the first category, might be introduced.

\section{APPENDIX}


This appendix discusses the impact of changes in relative sectoral productivity on the structure of production in the Rowthorn-Wells model. The issue is important for any modelling of economic development, and in particular, for the analysis of the postcommunist transition.

According to the definition of the joint share of agriculture and services in employment presented in the text (formula 8) we can write that the first derivative of $\varphi$ with respect to parameter $\lambda$ is:

$$
\frac{\partial \varphi}{\partial \lambda}=-\frac{\gamma}{f y_{0}} \alpha t e^{-\lambda \alpha t}+(1-c) \alpha t \frac{c e^{(\lambda-1) \alpha t}}{\left(1-c+c e^{(\lambda-1) \alpha t}\right)^{2}}
$$

This implies that we can distinguish four cases.

First, if $\frac{\gamma}{f y_{0}} e^{-\alpha t}<\frac{1-c}{2}\left(c^{2}-2 c+3-\sqrt{\left(c^{2}-2 c+3\right)^{2}-4}\right)$, than $\frac{\partial \varphi}{\partial \lambda}>0$, and in consequence the share of industrial employment always decreases as a function of $\lambda$.

Second, if

$$
\frac{1-c}{2}\left(c^{2}-2 c+3-\sqrt{\left(c^{2}-2 c+3\right)^{2}-4}\right)<\frac{\gamma}{f y_{0}} e^{-\alpha t}<\frac{1-c}{2}\left(c^{2}-2 c+3+\sqrt{\left(c^{2}-2 c+3\right)^{2}-4}\right)
$$

than function $\varphi$ has a minimum at

$$
\lambda_{1}=\frac{1}{\alpha t} \ln \frac{\left(\gamma / f y_{0}\right)(1-c)+\sqrt{\left(\gamma / f y_{0}\right)(1-c)^{3} e^{\alpha t}}}{1-c-\left(\gamma / f y_{0}\right) c e^{-\alpha t}},
$$

or, equivalently, the share of industrial employment has a maximum at this point.

The third case is when

$$
\frac{1-c}{2}\left(c^{2}-2 c+3+\sqrt{\left(c^{2}-2 c+3\right)^{2}-4}\right)<\frac{\gamma}{f y_{0}} e^{-\alpha t}<-1+\frac{1}{c} .
$$


Then, function $\varphi$ has a minimum at $\lambda_{1}$ given by (A2) and maximum at $\lambda_{2}=\frac{1}{\alpha t} \ln \frac{\left(\gamma / f y_{0}\right)(1-c)-\sqrt{\left(\gamma / f y_{0}\right)(1-c)^{3} e^{\alpha t}}}{1-c-\left(\gamma / f y_{0}\right) c e^{-\alpha t}}$.

In other words, the share of industrial employment has a maximum at $\lambda_{1}$ and minimum at $\lambda_{2}$.

Finally (the forth case), the share of industrial employment in the total employment grows monotonically as a function of $\lambda$, when $\frac{\gamma}{f y_{0}} e^{-\alpha t}>-1+\frac{1}{c}$ (function $\varphi$ decreases as a function of $\lambda$ ).

At this stage, the question arises of which of the aforementioned cases is most likely in the case of the post-communist countries characterised by low values of demand for services $(c)$ and agriculture $(\gamma)$, and high employment rate $f$. First of all, it is easy to notice that the forth case is very unlikely, especially if we consider higher values of $t$, corresponding to medium stage of technological development. Same applies to the third case, given that the demand for agriculture is low and, especially, that we take into account medium stage of technological development ( $t$ is relatively high).

In the light of that, we are restricted to the first two cases, that is when $\frac{L_{i}}{L}$ function has only the maximum (case 2) or it is a decreasing function (case 1). Furthermore, even is it more likely that the condition defining case 2 is satisfied for small $t$, in case of post-communist economies, we are discussing higher values of $t$, and the increase in the time parameter will push us very quickly from case 2 to the case when the share of industry employment decreases over time (case 1). Therefore, this is the case we focused on in the text. 


\section{REFERENCES}

Aghion, Philippe and Blanchard, Olivier J., "On the Speed of Transition in Eastern Europe", Working Paper No. 6, London: EBRD, 1993.

Andreff, Wladimir, "Nominal and Real Convergence - At What Speed". In: Jozef von Brabant, Ed., Remaking Europe: The European Union and the Transition Economies, Boulder: Rowman and Littlefield, 1999.

Berg, Andrew, Borenstsztein, Eduardo, Sahay, Ratna and Zettelmeyer, Jeromin, "The Evolution of Output in Transition Economies: Explaining the Differences", Working Paper No. 73, Washington: IMF, 1999.

Blanchard, Olivier J. The Economics of Post-Communist Transition. Oxford: Oxford University Press, 1997.

Blanchard, Olivier and Kremer, Michael, "Disorganisation", Quarterly Journal of Economics, 112, 4: 1091-1126, November 1997.

Dohrn, Roland, and Heilemann, Ullrich, "Structural Change in Eastern Europe”. In: Bernhard Heitger and Leonard Waverman, German Unification and the International Economy, pp. 83-112, London: Routledge, 1993.

Dohrn, Roland, and Heilemann, Ullrich, “The Chenery Hypothesis and Structural Change in Eastern Europe”, Economics of Transition, 4, 2: 411-425, 1996.

Driffill, John and Miller, Marcus, "No Credit for Transition: The Maastricht Treaty and German Unemployment”, Discussion Paper No. 1929, London: CEPR, 1998. 
European Bank for Reconstruction and Development, Transition Report. Enterprise Performance and Growth, London: EBRD, 1997.

European Bank for Reconstruction and Development, Transition Report. Financial Sector in Transition, London: EBRD, 1998.

European Bank for Reconstruction and Development, Transition Report. Ten Years of Transition, London: EBRD, 1999.

Gomulka, Stanislaw, “The Puzzles of Fairly Fast Growth and Rapid Collapse Under Socialism", Working Paper No. EE 6, Washington D.C: World Bank, Policy Research Department, 1991.

Grafe, Clemens, and Wyplosz, Charles, “The Real Exchange rate in Transition Economies”, Discussion Paper No. 395, London: Centre for Economic Performance, London School of Economics, 1998.

Gregory, Paul R. and Stuart, Robert C., Comparative Economic Systems, Boston: Houghton Mifflin, 1995.

Havrylyshyn, Oleh, Izvorski, Ivailo and van Rooden, Ron, "Recovery and Growth in Transition Economies 1990-1997: A Stylized Regression Analysis”, Working Paper No. 141, Washington D.C: IMF, 1998.

International Labour Office, World Employment 1996/1997. National Policies in a Global Context, Geneva: ILO, 1996.

Jackman, Richard, “Unemployment and Restructuring”, in: Peter Boone, Stanislaw Gomulka, and Richard Layard, Eds., Emerging from Communism. Lessons from Russia, China and Eastern Europe, Cambridge MA : MIT Press, 1998. 
Jackman, Richard, and Pauna, Catalin, "Labour market policy and the reallocation of labour across sectors", In Salvatore Zecchini, Ed., Lessons from the Economic Transition, Dordrecht: Kluwer, pp.373-392, 1997.

Mickiewicz, Tomasz, "Structural Convergence between Accession Countries and the EU”, Working Paper No. 01/01, Manchester: MET-Network Series, 2001.

Mickiewicz, Tomasz, and Bell, Janice, Unemployment in Transition. Restructuring and Labour Markets in Central Europe, Amsterdam: Harwood Academic Publishers, 2000.

Nuti, Mario, Transition Laggards: The Cases of Belarus and Uzbekistan: Why Don't They Change and How Do They Work?, Mimeo, London: London Business School, 1999.

Rodrik, Dani, "The Dynamics of Political Support for Reforms in Economics in Transition”, Journal of the Japanese and International Economies, 9, 4: 403$425,1995$.

Rostowski, Jacek and Nikolic, Milan, "Macroeconomic Shocks and Policy Responses During Transition; A Cross-Country Comparison”, In: Leszek Balcerowicz, Cheryl W. Gray, Iraj Hoshi, Eds., Enterprise Exit Process in Transition Economies, Budapest: CEU Press, 1998.

Rowthorn, Robert E. and Wells John R., De-Industrialization and Foreign Trade, Cambridge: Cambridge University Press, 1987.

Ruggerone, Luigi, “Unemployment and Inflationary Finance Dynamics at the Early Stages of Transition”, Economic Journal, 106, 1: 483-494, March 1996. 
William Davidson Institute Working Paper 383

Sachs, Jeoffrey, Poland's Jump to the Market Economy, Cambridge MA: MIT Press, 1994. 


\section{ENDNOTES}

\footnotetext{
${ }^{1}$ This is a long-term perspective. In shorter time spans, the income-elasticity of demand for food may appear to be different.
}

${ }^{2}$ One particular problem, we will ignore in the theoretical section is that in the Rowthorn-Wells model, aggregate value-added is an additive function of sectoral value-added. In a more general framework, we would have: $V=f\left(E_{1}, E_{2}, \ldots, E_{n}\right)$, where $V$ is value-added, $E$ corresponds to share of employment in a sector of economic activity and function $f$ may be either additive, or not. In the latter case, there are complementarities between sectors. For instance, efficiency of manufacturing may be enhanced by the existence of developed financial sector, other business-oriented services, transport services and educational system.

${ }^{3}$ For empirical examples and more discussion on data, seeMickiewicz and Bell, 2000, Chapter 3.

${ }^{4}$ Rowthorn-Wells 1987 show Figure A2.4b, where shifts in $\lambda$ lead to unambiguous positive shifts in $\mathrm{Li} / \mathrm{L}$ as a function of $\mathrm{Z} / \mathrm{L}$. While possible, that it is not a typical case for values of parameters consistent with stylised facts.

${ }^{5}$ For an overview of alternative/complementary explanations of 'transitional recessions' seeRostowski and Nikolic, 1998. For new theories based on disorganisation: Blanchard and Kremer, 1997.

${ }^{6}$ The difference in shares of industry between the Soviet block and the rest of world would be even more striking with non-employment added as a fourth sector, as employment rates were exceptionally high in the socialist countries. Employment rates were represented by coefficient $f$ in the formal model.

${ }^{7}$ The trend line depicted on the graph includes former communist economies. When the socialist countries are excluded from the sample, coefficient of determination increases from 0.15 to 0.29.

${ }^{8}$ Similarly to Figure 2, when the socialist countries are excluded, coefficient of determination for the trendline increases from 0.24 to 0.42 .

${ }^{9}$ The flows in and out of employment (changes in the employment rates) are left aside. That is an interesting topic for future work. Here, only the composition of labour force is analysed. Therefore, restructuring means shedding labour in one sector, taking up in another or both. This will be elaborated further in the next sections of this paper. 


\footnotetext{
${ }^{10}$ Here, as characterised by the Northern EU Group in 1998.

${ }^{11}$ Jackman and Pauna (1997) do not provide formula for their index, but it is easy to derive using their
} Table A.

${ }^{12}$ For lack of space, we do not discuss the intuition behind the indices; seeMickiewicz (2001) for more details. Generally, the sectors of employment, which are most similar between the fourNorhern EU economies, are: trade, transport, finance and construction. Furthermore, the comparison between Northern EU and Central European transition countries reveals that most pronounces differences are in shares of finance, real estate and other business services.

${ }^{13}$ For 1994, the indices reported here may differ from those obtained by Jackman and Pauna for two reasons. First, here, the Northern EU 1998 structure was used for both 1998 and 1994, to avoid a problem of "moving goalposts." In fact, RI are not affected (in terms of ranking) by the choice of a year, see Mickiewicz, Bell (2000) for 1997. We are interested in the convergence process towards the structures prevailing today. Second, the number of categories is doubled, as RI here are based on ISIC3 instead of ISIC-2 classifications. Thus, the indices could show that more restructuring is required, as there is more cross-sectoral movement. However, in practice the impact of this factor is negligible, as the categories which are expected to shed labour remain the same (primary sector, manufacturing).

${ }^{14}$ EBRD indicators relate to: large-scale privatisation, small-scale privatisation, governance and enterprise restructuring, price liberalisation, trade and foreign exchange system, competition policy, banking reform and interest rate liberalisation, securities markets and non-bank financial institutions. The scores are: 1, 1+, 2-, 2, 2+, 3-, 3, 3+, 4-, 4, 4+. Here, minuses were transformed into -0.333 and pluses into +0.333 . Nuti (1999) uses a different transformation for his comparisons between reforms and GDP growth: pluses into +0.5 and minuses into -0.5 . However that eliminates any distinction between scores different than round numbers.

15 This conclusion is supported by one more interesting distinction. The correlation coefficients between RI-1998 and the three individual indicators were: with large-scale privatisation -0.66, smallscale privatisation -0.81 , and governance and enterprise restructuring -0.86 . The same order of results was obtained for 1997 . Thus, it is clear that privatisation of large enterprises was probably less relevant 
William Davidson Institute Working Paper 383

than both introduction of efficient corporate governance and full implementation of small-scale privatisation. 